\title{
Altered liver expression of genes involved in lipid and glucose metabolism in mice with partial IGF-1 deficiency: an experimental approach to metabolic syndrome
}

\author{
J. Rodríguez De Ita ${ }^{1 \dagger}$, I. Castilla-Cortázar ${ }^{1,2^{*}}$, G. A. Aguirre ${ }^{1}$, C. Sánchez-Yago ${ }^{3}$, M. Olleros Santos-Ruiz², \\ L. Guerra-Menéndez ${ }^{3}$, I. Martín-Estal ${ }^{1}$, M. García-Magariño ${ }^{1}$, V. J. Lara-Díaz ${ }^{1}$, J. E. Puche ${ }^{3}$ and U. Muñoz ${ }^{3}$
}

\begin{abstract}
Background: Insulin growth factor 1 (IGF-1) has multiple effects on metabolism. Much evidence suggests that the deficiency of this hormone increases insulin resistance, impairs lipid metabolism, augments oxidative damage and deregulates the neuro-hormonal axis. An inverse relationship between IGF-1 levels and the prevalence of Metabolic Syndrome (MetS) with its cardiovascular complications has been identified. However, the underlying mechanisms linking IGF-1 and MetS are still poorly understood. In order to elucidate such mechanisms, the aim of this work was to study, in mice with partial IGF-1 deficiency, liver expression of genes involved in glucose and lipid metabolism as well as serum levels of glucose, triglycerides and cholesterol, as well as liver malondialdehyde (MDA) levels, as a marker for oxidative damage.
\end{abstract}

Methods: Three experimental groups were studied in parallel: Controls (CO), wild type mice (igf-1 $\left.{ }^{+/+}\right)$; untreated heterozygous mice $\left(\mathrm{Hz}\right.$, igf-1 $\left.1^{+-}\right)$and $\mathrm{Hz}\left(i g f-1^{+/-}\right)$mice treated with low doses of IGF-1 for 10 days $(\mathrm{Hz}+\mathrm{IGF}-1)$.

Results: A reduction of IGF-1 serum levels in the $\mathrm{Hz}$ group was found, which was normalized by IGF-1 therapy. Serum levels of glucose, triglycerides and cholesterol were significantly increased in the untreated $\mathrm{Hz}$ group as compared to both controls and $\mathrm{Hz}+$ IGF-1 groups. The expression of genes involved in gluconeogenesis, glycogenolysis, lipid synthesis and transport, and catabolism were altered in untreated $\mathrm{Hz}$ animals and the expression of most of them was normalized by IGF-1 therapy; MDA was also significantly increased in the $\mathrm{Hz}$ untreated group.

Conclusions: The mere partial IGF-1 deficiency is responsible for the reduction in the expression of genes involved in glucose and lipid metabolism, resulting in dyslipidemia and hyperglycemia. Such genetic alterations may seriously contribute to the establishment of MetS.

Keywords: Metabolism, Metabolic syndrome, IGF-1, Type 2 diabetes, Growth hormone, Gluconeogenesis, Glucogenolysis, Glucose-6-phosphate (G6P), Phosphoenolpyruvate carboxykinase (PEPCK), ATP-citrate lyase (Acly), Acetyl-CoA acyltransferase (Acaa1b), Insulin resistance, Oxidative damage, Dyslipidemia

\footnotetext{
*Correspondence: iccortazar@itesm.mx; iccortazar@gmail.com

†J. Rodríguez De Ita, I. Castilla-Cortazar contributed equally to this work

${ }^{1}$ Escuela de Medicina, Tecnologico de Monterrey, Avenida Morones

Prieto No. 3000 Pte. Col. Los Doctores, 64710 Monterrey, Nuevo León,

México

Full list of author information is available at the end of the article
} 


\section{Background}

Insulin-like growth factor 1 (IGF-1) is an anabolic hormone mainly produced in the liver by growth hormone (GH) endocrine stimulus [1]. IGF-1 possesses multiple effects on metabolism [2].

Interestingly, GH and insulin act in symphony with IGF-1 to produce a harmonious and coordinated response [3-5]. There is a yearly increasing number of studies suggesting the role of IGF-1 in metabolic coordination [2]. Accumulated evidence has proven an IGF-1 implication in lipid and glucose metabolism $[5,6]$.

Recent data support that IGF-1 deficiency increases insulin resistance, impairs lipid metabolism, promotes oxidative damage and deregulates the neuro-hormonal axis [7-9]. IGF-1 circulating levels decrease with aging, and such a decrease is associated with insulin resistance and dyslipidemia. Interestingly, IGF-1 replacement therapy improved the overall homeostasis [7]. On the other hand, an inverse relationship between IGF-1 circulating levels and incidence of metabolic syndrome (MetS) with liver steatosis, insulin resistance, hyperlipidemia and visceral obesity has been identified [10-13]. In addition, cardiovascular complications of MetS have been also reported [14].The majority of the studies have found that patients with MetS suffer more from cardiovascular disease (CVD) and an increased predisposition towards developing it [15-18].

Moreover, the MetS is also a good predictor for the development of type 2 Diabetes (T2D) [19-21]. Insulin resistance, hyperinsulinemia, dyslipidemia and obesity precede the progression to T2D [22] and the presence of MetS increases up to five fold the risk for T2D as compared to controls [21, 22]. The risk is increased up to sixto sevenfold, if insulin resistance is also present [23].

On the other hand, MetS is strongly related with insulin resistance and obesity, as well as non-alcoholic fatty liver disease (NAFLD), polycystic ovarian syndrome, hypogonadism and microvascular disease among others [23-25].

In this physiopathological context the underlying mechanism between the IGF-1 deficiency and the establishment of MetS is poorly understood. In order to gain more insight into these mechanisms, an experimental model of partial IGF-1 deficiency was used [26]. The experimental protocol included three groups of adult mice (28 \pm 6 weeks old): untreated, heterozygotes $\left(\right.$ igf $^{+/-}$) mice with partial IGF-1 deficiency; heterozygotes (igf1 ${ }^{+-}$) mice treated with IGF-1; and wild type $\left(\right.$ igf $^{+/+}$) mice that served as controls.

The specific aim of this work was to investigate whether the mere IGF-1 deficiency is able to alter the expression of genes involved in glucose and lipid metabolic pathways. Thus, liver gene expression studies carried out by microarray technique followed by RT-qPCR confirmation; serum levels of IGF-1, glucose, cholesterol and triglycerides were determined as well as MDA in liver homogenates, all studied in the three experimental groups.

\section{Methods}

\section{Animals and experimental design}

The experimental model was established and characterized as previously reported [26]. Briefly, IGF-1 heterozygous mice were obtained by cross-breeding transgenic mice, line 129SV and Igf ${ }^{\text {tm1Arge }}$ [27].

Animal genotype determination was performed by PCR analysis (Applied Biosystems, 2720 Thermal Cycler, Spain). DNA was extracted from a piece of tail and specific primers were used to identify both igf- 1 and neo genes (Extract-N-Amp TM Tissue PCR KIT Sigma, USA).

Animals were housed in cages in a room with a 12-h light/dark cycle, constant humidity (50-55 \%) and temperature $\left(20-22{ }^{\circ} \mathrm{C}\right.$ ). Food (Teklad Global $18 \%$ protein rodent diet, Harlan Laboratories, Spain) and water were given ad libitum. All experimental procedures were performed in compliance with The Guiding Principles for Research Involving Animals and approved by the Bioethical Committee from our institution.

Three groups of male mice $28 \pm 6$ weeks old were included in the experimental protocol: Controls wild type mice $\left(\mathrm{CO}\right.$, igf $\left.-1^{+/+}, \mathrm{n}=10\right)$; untreated heterozygotes mice $\left(\mathrm{Hz}\right.$, igf- $\left.1^{+/-}, \mathrm{n}=10\right)$ and heterozygous animals subcutaneously treated with IGF-1 ( $2 \mu \mathrm{g} / 100 \mathrm{~g}$ body weight/day) for 10 days $\left(\mathrm{Hz}+\mathrm{IGF}-1\right.$, igf- $\left.1^{+-}, \mathrm{n}=10\right)$. Both the $\mathrm{CO}$ and $\mathrm{Hz}$ groups received vehicle (succinate buffer). IGF-1 was provided by Chiron Corporation, USA.

On the 11th day mice were weighed, blood was obtained from submandibular vein and thereafter animals were sacrificed by cervical dislocation. The liver was carefully dissected out, weighed (Denver Instrument, Germany) and divided in 2 sections: left lobe was stored in RNAlater (Qiagen-Izasa, Spain) at $-80{ }^{\circ} \mathrm{C}$ for microarray and PCR RNA analyses, and right lobe for histology and MDA assessment.

\section{Serum and liver analysis}

Serum levels of IGF-1 were determined by ELISA in a Varioskan spectrophotometer (Thermo Scientific, Finland), following specific commercial assay protocol instructions (Chiron Corporation, USA).

The serum concentrations of glucose, triglycerides and cholesterol were determined by routine laboratory methods by a COBAS INTEGRA 400 Plus auto analyzer (Roche-Hitachi, Germany), Calibration Reagents (Roche) and Cassettes of the same brand. 


\section{Malondialdehyde levels}

Malondialdehyde (MDA) was used as an index of lipid peroxidation and was measured after heating samples at $45{ }^{\circ} \mathrm{C}$ for $60 \mathrm{~min}$ in acid medium. It was quantitated by a colorimetric assay using LPO-586 (Bioxytech; OXIS International Inc., Portland, OR, USA), which, after reacting with MDA, generates a stable chromophore that can be measured at $586 \mathrm{~nm}$ (Hitachi U2000 Spectro; Boehringer Mannheim). Determinations were performed in homogenates of liver tissue in Tris- $\mathrm{HCl}$ solution $(1 \mathrm{~g}$ of liver tissue per $10 \mathrm{ml}$ ) centrifuged at $3000 \mathrm{~g}$ during 10 min at $4{ }^{\circ} \mathrm{C}$.

\section{Gene expression studies Microarray analysis}

Liver mRNA was isolated from animals belonging to the three experimental groups in accordance with the protocol outlined in RNAqueousH-Micro Kit (Ambion, USA). Technical procedures for microarray analysis, including quality control of mRNA, labeling, hybridization and scanning of the arrays were performed according to standard operating procedures for Affymetrix protocols (GeneChipH Expression Analysis Manual, Affymetrix, USA). The mRNAs were profiled using Affymetrix HT MG-430. The array signals were normalized using Robust Multichip Averages [28] and batch-effects of the three replicates were corrected using ComBat [29]. Differentially expressed genes between $\mathrm{Hz}+\mathrm{IGF}-1$ and $\mathrm{CO}$ samples were selected using FDR-corrected $p$ value of 0.01 (p value of $<0.05$ ).

\section{Total RNA extraction, reverse transcription and quantitative real time polymerase chain reactions (RT-qPCR)}

Hepatic lobules were cryopreserved in RNAlater (Qiagen-Izasa, Spain). The day performing PCR determinations hepatic samples were homogenized with TRIzol reagent (Invitrogen, UK) by Tissue Lyser LT (QiagenIzasa, Spain) and RNA was extracted and purified using the (Qiagen), RNeasy Mini Kit including digestion with RNase-free DNase, following the manufacturer's instructions. RNA quality was checked by the A260:A280 ratio and with Bioanalyzer 2100 (Agilent Technologies Inc., USA). Purified RNA was then converted to cDNA by using the RNA-to-DNA EcoDryTM Premix (Clonetech Labs, USA) for qPCR assays. Quantitative real time PCR assays were performed in a 3100 Avant Genetic Analyzer (Applied Biosystems Hispania, Spain). The thermal profile consisted of an initial 5 min melting step at $95^{\circ} \mathrm{C}$ followed by 40 cycles at $95^{\circ} \mathrm{C}$ for $10 \mathrm{~s}$ and $60{ }^{\circ} \mathrm{C}$ for $60 \mathrm{~s}$.

Specific Taqman ${ }^{\circledR}$ probes for the selected genes (Acaa1b, Acat1, Acsl1, Acot9, Fabp1, Fabp5, Hmgcs1, Lpl,
Lrp1, Pcsk9, Ankra2, Hmgcr, G6pc, Pck1, Pdk4, Acly, Igf1, $I g f b p 1$, and $I g f b p 3)$ were supplied by Applied Biosytems.

The relative mRNA levels of the genes of interest were normalized to Tbp expression using the simplified comparative threshold cycle delta, cycle threshold (CT) method [2-( $2^{-\mathrm{CT}}$ gene of interest $-\Delta \mathrm{CT}$ actin) $]$ [30]. Tbp was selected fot endogenous control after carefully analyzing 12 genes (Actb, B2m, Gapdh, Gusb, Hsp90ab1, Ldha, Pgk1, Ppih, Sdha, Tbp, Tfrc, and Ubc), which are widely used as housekeeping genes. Only 5 out of these 12 did not vary their expression when comparing $\mathrm{Hz}$ with Controls. We assayed those 5 genes and selected the one, which showed more stable and reproducible values, which was Tbp, a very stable gene coding for a transcription factor that binds the TATA box.

\section{Statistical analysis}

All data represent mean \pm SEM. Statistical analysis was performed on SPSS 20 (Statistical Package for Social Sciences, USA). Significance was estimated by the Kruskal-Wallis ANOVA followed by a post hoc test for distribution-free multiple comparisons (Bonferroni). Correlation between IGF-1 and weight was analyzed by Spearman test. Differences were considered significant at a level of $\mathrm{p}<0.05$.

\section{Results}

\section{IGF-1 circulating levels, body and liver weight}

According to previous series [26, 31] $28 \pm 6$ weeks old $\mathrm{Hz}$ mice showed a significant decrease of circulating levels of IGF-1 as compared to CO. The exogenous administration of low doses of IGF-1 normalized IGF-1 serum levels in $\mathrm{Hz}+\mathrm{IGF}-1$. Thus, the usefulness of the substitutive IGF-1 therapy at low doses was confirmed (see Fig. 1a).

As an anabolic hormone, IGF-1 deficiency induced body weight loss in untreated $\mathrm{Hz}$ mice as compared to controls.

Interestingly, IGF-1 treatment for only 10 days was able to restore the bodyweight (CO: $39.76 \pm 2.45 \mathrm{~g}$ vs. $\mathrm{Hz} 33.59 \pm 1.06$ g, p < 0.01; Hz + IGF-1: $39.52 \pm 1.48 \mathrm{~g}$ vs. $\mathrm{Hz} \mathrm{p}<0.01)$. Absolute liver weight was significantly decreased in $\mathrm{Hz}$ mice as compared to $\mathrm{CO}(\mathrm{Hz}$ : $1.63 \pm 0.09$ g vs. CO: $1.92 \pm 0.16$ g, $\mathrm{p}<0.05$ ), while differences between $\mathrm{CO}$ and $\mathrm{Hz}+\mathrm{IGF}-1$ mice were not found $(\mathrm{Hz}+\mathrm{IGF}-1: 1.93 \pm 0.19 \mathrm{~g}, \mathrm{p}=\mathrm{ns})$.

\section{Serum and liver analysis}

Table 1 summarizes serum glucose, triglycerides and cholesterol values and hepatic levels of MDA, as a marker of oxidative damage in the three experimental groups. Untreated $\mathrm{Hz}$ mice showed a significant increase in all 

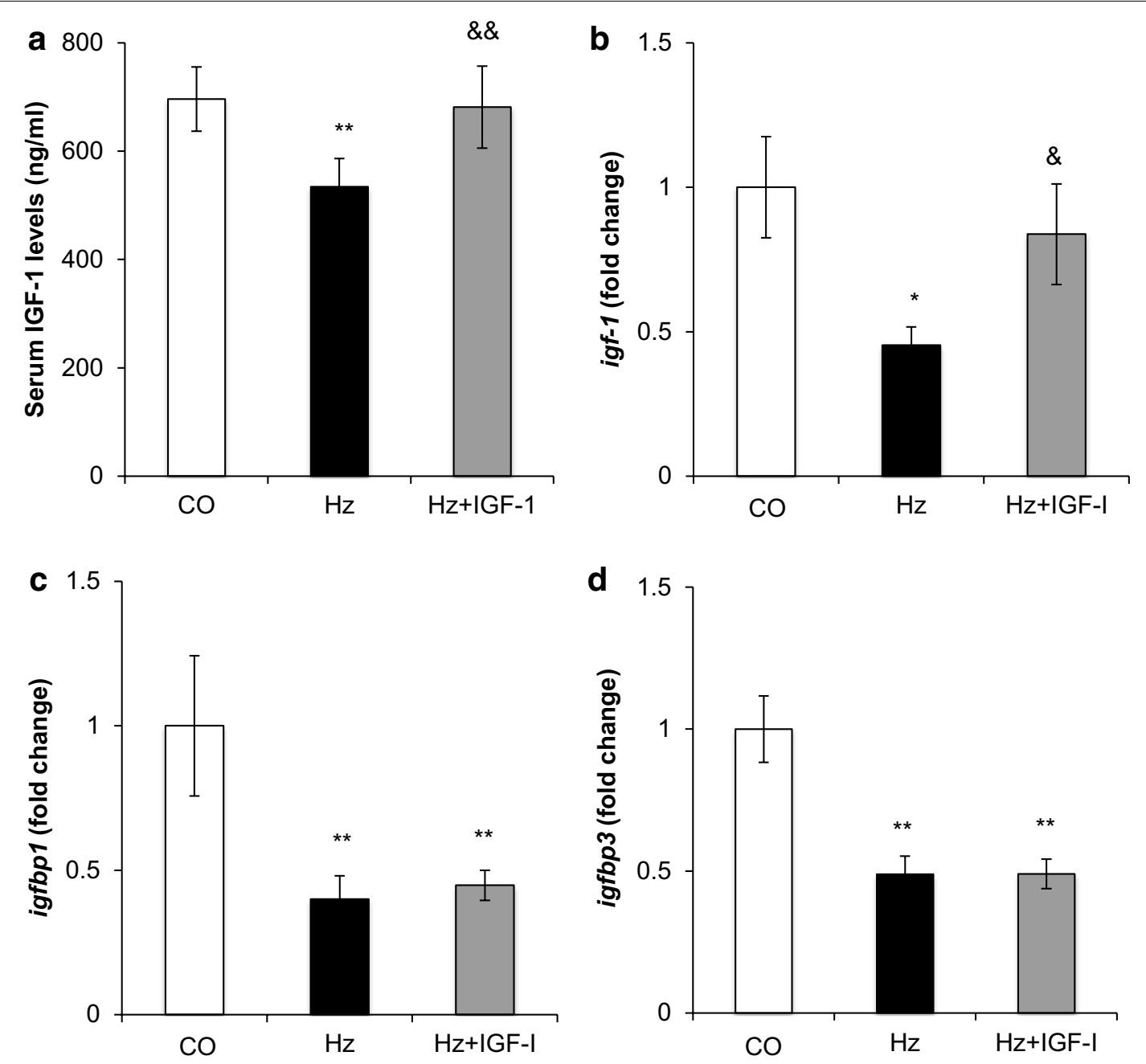

Fig. 1 IGF-1 serum levels. IGF-1 and IGFBPs liver gene expression. a IGF-1 circulating levels at the end of the treatment determined in the three experimental groups. b Liver expression of igf-1, b igfbp 1 and, $\mathbf{d}$ igfbp3 genes in the three experimental groups determined by RT-qPCR and expressed as relative values compared to controls (fold change). ${ }^{* *} p<0.01,{ }^{*} p<0.05 \mathrm{vs}$. CO; ${ }^{\&} p<0.01,{ }^{\&} p<0.05 \mathrm{vs} . \mathrm{Hz}$

Table 1 Serum and liver parameters for the three experimental groups

\begin{tabular}{lccr}
\hline & Controls & Untreated IGF-1 deficient mice & $\begin{array}{c}\text { Treated IGF-1 } \\
\text { deficient mice }\end{array}$ \\
\hline Glucose $(\mathrm{mg} / \mathrm{dL})$ & $83.07 \pm 5.62$ & $123.91 \pm 11.27^{* *}$ & $93.59 \pm 3.95^{\&}$ \\
Triglycerides $(\mathrm{mg} / \mathrm{dL})$ & $235.70 \pm 11.50$ & $291.01 \pm 21.50^{*}$ & $254.11 \pm 12.20^{\&}$ \\
Cholesterol $(\mathrm{mg} / \mathrm{dL})$ & $221.76 \pm 8.27$ & $271.43 \pm 12.76^{*}$ & $235.28 \pm 4.86^{\&}$ \\
MDA (UM/mg protein/mL) & $0.12 \pm 0.02$ & $0.16 \pm 0.02^{*}$ & $0.07 \pm 0.004^{\&}$ \\
\hline
\end{tabular}

Control group, WT mice; Hz group including untreated mice with partial IGF-1 deficiency; Hz + IGF-1 group: Hz mice treated with low doses of IGF-1 during 10 days

${ }^{* *} \mathrm{p}<0.01,{ }^{*} \mathrm{p}<0.05$ vs. Controls; ${ }^{\&} \mathrm{p}<0.05$ vs. Hz group

these parameters. IGF-1 replacement therapy had the property to reduce, although not to completely abolish, the increases in glucose, triglycerides and cholesterol. Furthermore, it was able to diminish hepatic MDA to similar levels to those found in controls.

\section{Liver gene expression studies}

Microarray technique revealed several genes (Table 2) either hypo- or hyper-expressed in $\mathrm{Hz}$ as compared to $\mathrm{CO}$ mice (fold change over \pm 1.5 ), as well as $\mathrm{Hz}+$ IGF-1 animals compared to the $\mathrm{Hz}$ group. 
Table 2 Liver expression of genes related to IGF-1

\begin{tabular}{|c|c|c|c|c|c|}
\hline Protein & Gene & $\begin{array}{l}\text { Hz vs. WT } \\
\text { (fold change) }\end{array}$ & p value & $\begin{array}{l}\mathrm{Hz}+\text { IGF vs. Hz } \\
\text { (fold change) }\end{array}$ & $\mathrm{p}$ value \\
\hline Insulin-like growth factor 1 & $(\operatorname{lgfi})$ & -2.48 & 0.0017 & 1.64 & 0.002 \\
\hline Insulin-like growth factor 2 & $(\operatorname{lgf2})$ & -1.35 & 0.14 & 1.48 & 0.16 \\
\hline Insulin-like growth factor binding protein 1 & $(\operatorname{lgfbp} 1)$ & -4.53 & 0.0001 & -2.2 & 0.0012 \\
\hline Insulin-like growth factor binding protein 2 & $(\operatorname{lgfbp2})$ & -1.18 & 0.015 & -1.02 & 0.37 \\
\hline Insulin-like growth factor binding protein 3 & (lgfbp3) & $=1.78$ & 0.012 & 1.33 & 0.011 \\
\hline Insulin-like growth factor binding protein 4 & (lgfbp4) & 1.13 & 0.33 & 1.35 & 0.29 \\
\hline Insulin-like growth factor binding protein 5 & $(\operatorname{lgfbp5)}$ & -1.37 & 0.10 & 1.37 & 0.17 \\
\hline Insulin-like growth factor binding protein 6 & (lgfbp6) & -1.10 & 0.31 & 1.19 & 0.12 \\
\hline Albumin & (Alb) & -1.06 & 0.12 & -1.01 & 0.14 \\
\hline Parvalbumin & (Pvalb) & -1.04 & 0.11 & -1.10 & 0.13 \\
\hline Lactalbumin, alpha & (Lalba) & -1.10 & 0.14 & 1.04 & 0.12 \\
\hline D site albumin promoter binding protein & $(D b p)$ & $\underline{2.33}$ & 0.05 & -1.16 & 0.19 \\
\hline
\end{tabular}

Control group, WT mice; Hz group including untreated mice with partial IGF-1 deficiency; Hz + IGF-1 group: Hz mice treated with low doses of IGF-1 during 10 days. Underlined values correspond to those with a fold-change $>1.5$, considered as a significant variation in the gene expression

\section{IGF-1 and main IGFBPs gene expression}

Among the genes with an altered expression, we firstly focused on those closely related to the physiology of IGF-1 (Table 2). Real time quantitative PCR was performed to confirm changes over \pm 1 .5-fold variance, such as IGF-1 and IGFBP-1 and IGFBP-3 (Fig. 1b-d).

Statistical differences were confirmed by RT-qPCR for $i g f-1, i g f b p 1$ and $i g f b p 3$ genes. In the $\mathrm{Hz}$ group, igf1 expression was found significantly reduced and, unexpectedly, IGF-1 replacement therapy increased hepatic igf-1 expression (Fig. 1b).

On the other hand, igfbp 1 and $i g f b p 3$ expressions were found significantly reduced in untreated $\mathrm{Hz}$ animals and substitutive IGF-1 treatment did not induce any change on the expression of these two genes (Fig. 1c, d).

\section{Expression of genes involved in glucose metabolism}

The expression of genes involved in glucose metabolism was analyzed by microarray analysis. RT-q PCR was performed to confirm changes over \pm 1.5 fold change (Table 3). Gene expression of $g 6 p c$ (glucose-6-phosphatase, catalytic), pck1 (phosphoenolpyruvate carboxykinase 1, cytosolic), pdk4 (pyruvatedehydrogenase kinase, isoenzyme 4) and acly (ATP citratelyase) was found significantly diminished in $\mathrm{Hz}$ as compared to $\mathrm{CO}$. Interestingly, low doses of IGF-1 were able to normalize all these values to those found in the $\mathrm{CO}$ group (Fig. 2).

\section{Lipid metabolism gene expression}

A significant decrease in expression of genes involved in lipid catabolism, such as acaa $1 b$ (acetyl-CoA acyltransferase 1), acat 1 (acetyl CoA acetyltransferase) was found (Fig. 3a). Hepatic expression of the acaa $1 b$ gen was normalized in animals deficient in IGF-1 when receiving replacement therapy for 10 days. No significant differences between $\mathrm{CO}$ and $\mathrm{Hz}+\mathrm{IGF}-1$ were found in acat1 expression.

Likewise, partial deficiency of IGF-1 was associated with liver hypoexpression of genes that code for enzymes involved in cholesterol synthesis: hmgcs1 (3-hydroxy3-methylglutaryl-CoA synthase1), hmgcr (3-hydroxy3-methylglutaryl-CoA reductase): see Fig. 3b; and those encoding low-density lipoprotein receptor related proteins, pcsk9 (proprotein convertase subtilisin/Kesin type 9) and lpr1 (low density lipoprotein receptor-related protein 1). The expressions of all these genes were normalized by IGF-1 replacement therapy (Figs. 3b, 4a).

\section{Fatty acid transport and triglyceride catabolism}

It was found that the partial IGF-1 deficiency resulted in the genetic downregulation of fabpl (fatty acid binding protein 1, liver) and an overexpression of fabp 5 (fatty acid binding protein 5, epidermal). RT-qPCR confirmed these findings and showed that fabp5 was sensitive to replacement therapy with IGF-1 (Fig. 4b).

Furthermore, animals with partial IGF-1 deficiency showed an overexpression of the lipoprotein lipase gene $(l p l)$ confirmed by RT-qPCR (Fig. 4c). No differences in the expression of genes encoding proteins involved in the regulation of fatty acid biosynthesis were found (Table 4).

\section{Discussion}

In the last decades many authors have tried to elucidate the involvement of different factors in the establishment of MetS including impaired glucose and lipid metabolism, lipotoxicity, steatosis, oxidative stress, obesity, interrupted neuro-hormonal regulation and altered intracellular $\mathrm{Ca}^{2+}$ trafficking [10-14]. 
Table 3 Liver expression of genes related to glucose metabolism

\begin{tabular}{|c|c|c|c|c|c|}
\hline Protein & Gene & $\begin{array}{l}\text { Hz vs. WT } \\
\text { (fold change) }\end{array}$ & $\mathrm{p}$ value & $\begin{array}{l}\mathrm{Hz}+\text { IGF vs. Hz } \\
\text { (fold change) }\end{array}$ & $\mathrm{p}$ value \\
\hline Fructosebisphosphatase 1 & $(F b p 1)$ & 1.40 & 0.02 & -1.49 & 0.01 \\
\hline Fructosebisphosphatase 2 & (Fbp2) & $\underline{1.64}$ & 0.017 & 1.06 & 0.42 \\
\hline Glucose-6-phosphatase, catalytic & (G6pc) & $=1.92$ & 0.001 & -1.71 & 0.0059 \\
\hline Glucose 6 phosphatase, catalytic, 3 & $(G 6 p c 3)$ & -1.01 & 0.56 & 1.31 & 0.017 \\
\hline Phosphoenolpyruvatecarboxykinase 1, cytosolic & $(P \subset k 1)$ & $=2.42$ & 0.001 & 1.35 & 0.08 \\
\hline Phosphoenolpyruvatecarboxykinase 2 (mitochondrial) & $(P \subset k 2)$ & -1.14 & 0.45 & 1.10 & 0.40 \\
\hline Pyruvate carboxylase & $(P C X)$ & -1.01 & 0.18 & 1.05 & 0.09 \\
\hline Pyruvate dehydrogenase kinase, isoenzyme 1 & $(P d k 1)$ & -1.46 & 0.0035 & 1.23 & 0.19 \\
\hline Pyruvate dehydrogenase kinase, isoenzyme 2 & $(P d k 2)$ & -1.17 & 0.03 & 1.33 & 0.035 \\
\hline Pyruvate dehydrogenase kinase, isoenzyme 3 & $(P d k 3)$ & 1.23 & 0.42 & -1.01 & 0.94 \\
\hline Pyruvate dehydrogenase kinase, isoenzyme 4 & $(P d k 4)$ & $=1.83$ & 0.03 & -1.01 & 0.85 \\
\hline Pyruvate dehyrogenase phosphatase catalytic subunit 2 & $(P d p 2)$ & -1.08 & 0.09 & 1.21 & 0.04 \\
\hline ATP citratelyase & (Acly) & $=1.67$ & 0.0007 & $\underline{1.60}$ & 0.006 \\
\hline Aconitase 1 & (Acol) & -1.30 & 0.38 & 1.17 & 0.23 \\
\hline Aconitase 2, mitochondrial & (Aco2) & -1.18 & 0.013 & 1.16 & 0.85 \\
\hline Dihydrolipoamide S-acetyltransferase & (Dlat) & 1.03 & 0.13 & -1.15 & 0.19 \\
\hline Dihydrolipoamidedehydrogenase & $(D / d)$ & -1.02 & 0.03 & 1.11 & 0.73 \\
\hline Dihydrolipoamide S-succinyltransferase & $(D / s t)$ & 1.14 & 0.40 & 1.41 & 0.01 \\
\hline Isocitratedehydrogenase 1 (NADP+), soluble & $(\mid d h 1)$ & 1.07 & 0.04 & -1.38 & 0.07 \\
\hline Isocitratedehydrogenase $2(\mathrm{NADP}+$ ), mitochondrial & $($ (Idh2) & -1.10 & 0.45 & 1.01 & 0.25 \\
\hline Isocitratedehydrogenase $3(\mathrm{NAD}+$ ) alpha & (Idh3a) & -1.21 & 0.09 & 1.06 & 0.01 \\
\hline
\end{tabular}

Control group, WT mice; $\mathrm{Hz}$ group including untreated mice with partial IGF-1 deficiency; $\mathrm{Hz}+$ IGF-1 group: Hz mice treated with low doses of IGF- 1 during 10 days. Underlined values correspond to those with a fold-change $>1.5$, considered as a significant variation in the gene expression

Lately, increasing evidence points to a central role of IGF-1 in the pathological pathways leading to the establishment of MetS [32]. Several recent studies have attempted to correlate low IGF-1 serum levels with MetS $[33,34]$. In this context, the present study was focused on determining how the IGF-1 deficiency "per se" could contribute to the establishment of MetS.

With this objective, it was used a recently characterized experimental model of haploinsufficiency in which mice hypoexpressing the $i g f 1$ gene (igf ${ }^{+/-}, \mathrm{Hz}=$ heterozygous) show low circulating IGF-1 levels [26, 31].

The IGF-1 deficiency correlated with a significant reduction in body weight [26] and the replacement therapy was able to restore both IGF-1 serum levels and body weight in accordance with previous results [31].

Data in this paper show that the mere IGF-1 deficiency in adult mice is responsible for altering the hepatic expression of genes involved in glucose and lipid metabolism leading to hypertriglyceridemia, hypercholesterolemia and hyperglycemia (Table 1 ). The IGF-1 therapy was able to revert all these parameters with only 10 days of treatment.

The adult mice used in this work lived within very controlled conditions (diet, drink, temperature) avoiding all exogenous insults. Consequently, all of the findings in this study are due to the mere IGF-1 deficiency.
One of the most noticeable results in this paper is that the mere IGF-1 deficiency reduced the liver expression of genes coding for phosphoenolpyruvate carboxykinase (PEPCK) and glucose-6-phosphatase (G6Pase), key enzymes involved in gluconeogenesis and both restored to normal values by IGF-1 therapy.

The net glucose release is the result of two simultaneous ongoing pathways that are tightly regulated. The liver produces glucose by breaking down glycogen (glycogenolysis) and by "de novo" synthesis of glucose (gluconeogenesis) from non-carbohydrate precursors such as lactate, amino acids and glycerol [35].

The rate of gluconeogenesis is mainly controlled by the activities of unidirectional enzymes such as PEPCK and G6Pase [36]. Pck1 is involved in the expression of the enzyme that catalyzes one of the rate limiting steps of gluconeogenesis, the conversion of oxaloacetate to phosphoenolpyruvate (PEP), while G6Pase catalyzes the final step of gluconeogenesis, the production of free glucose from glucose-6-phosphate (G6P). Until now, it is well known that the genes of these gluconeogenic enzymes are controlled at the transcriptional level by hormones, mainly insulin, glucagon and glucocorticoids [36].

Interestingly, it is well recognized that insulin decreases the expression of $g 6 p c$ and $p c k 1$. Results in this paper 

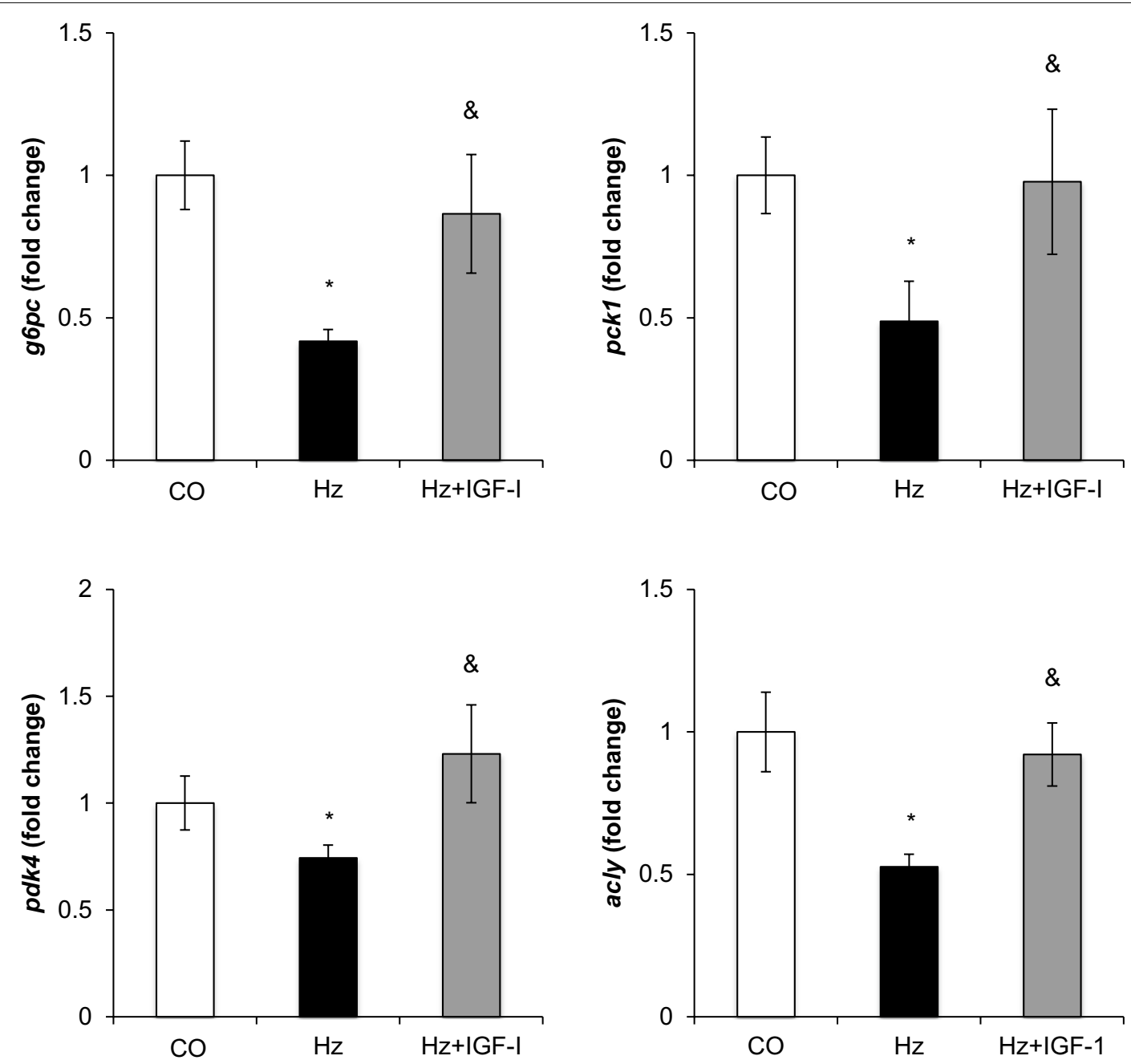

Fig. 2 Liver expression of genes involved on gluconeogenesis and glycogenolysis. Expression of g6pc (Glucose-6-phosphatase), pck1 (Phosphoenolpyruvate-carboxylase 1), pdk4 (Pyruvate dehydrogenase kinase isoenzyme 4) and acly (ATP-citrate lyase) genes determined by RT-qPCR and expressed as relative values compared to controls (fold change). ${ }^{*} p<0.05 \mathrm{vs}$. CO; ${ }^{\circledR} p<0.05 \mathrm{vs}$. Hz

demonstrate that IGF-1 induces the opposite effects since the IGF-1 deficit reduces the expression of $g 6 p c$ and $p c k 1$. Thus, these activities of IGF-1 are not "insulin like" but rather antagonistic. These findings reinforce the role of IGF-1 in glucose homeostasis, recently suggested by many authors [5, 37-40].

It is well known that insulin and IGF-1 share structural homology and interact with the same membrane receptors, albeit with different affinities. Insulin and IGF-1 exert complementary biological actions, which are pathologically important when one of the hormone levels drops significantly [14].

In this sense, a different result within this paper, that deserves an especial mention, is the hypoexpression of $p d k 4$ in IGF-1 deficient mice, which IGF-1 replacement therapy was able to revert. This gene ( $p d k 4)$ encodes pyruvate-dehydrogenase complex (PDK). PDK is an emerging target for the treatment of MetS. To maintain a steady-state concentration of adenosine triphosphate during the feed-fast cycle, cells require efficient utilization of fatty acid and glucose, which is controlled by PDK [41]. Particularly the $p d k 4$ gene encodes PDK that converts pyruvate, CoA and oxidized nicotinamide adenine dinucleotide $\left(\mathrm{NAD}^{+}\right)$into acetyl-CoA, the reduced form of nicotinamide adenine dinucleotide (NADH) and carbon dioxide. The activity of PDK is upand downregulated by pyruvate dehydrogenase kinase and pyruvate dehydrogenase phosphatase, respectively. In addition, pyruvate is a key intermediate of glucose oxidation and an important precursor for the synthesis of glucose, glycerol, fatty acids and nonessential amino acids [41]. 

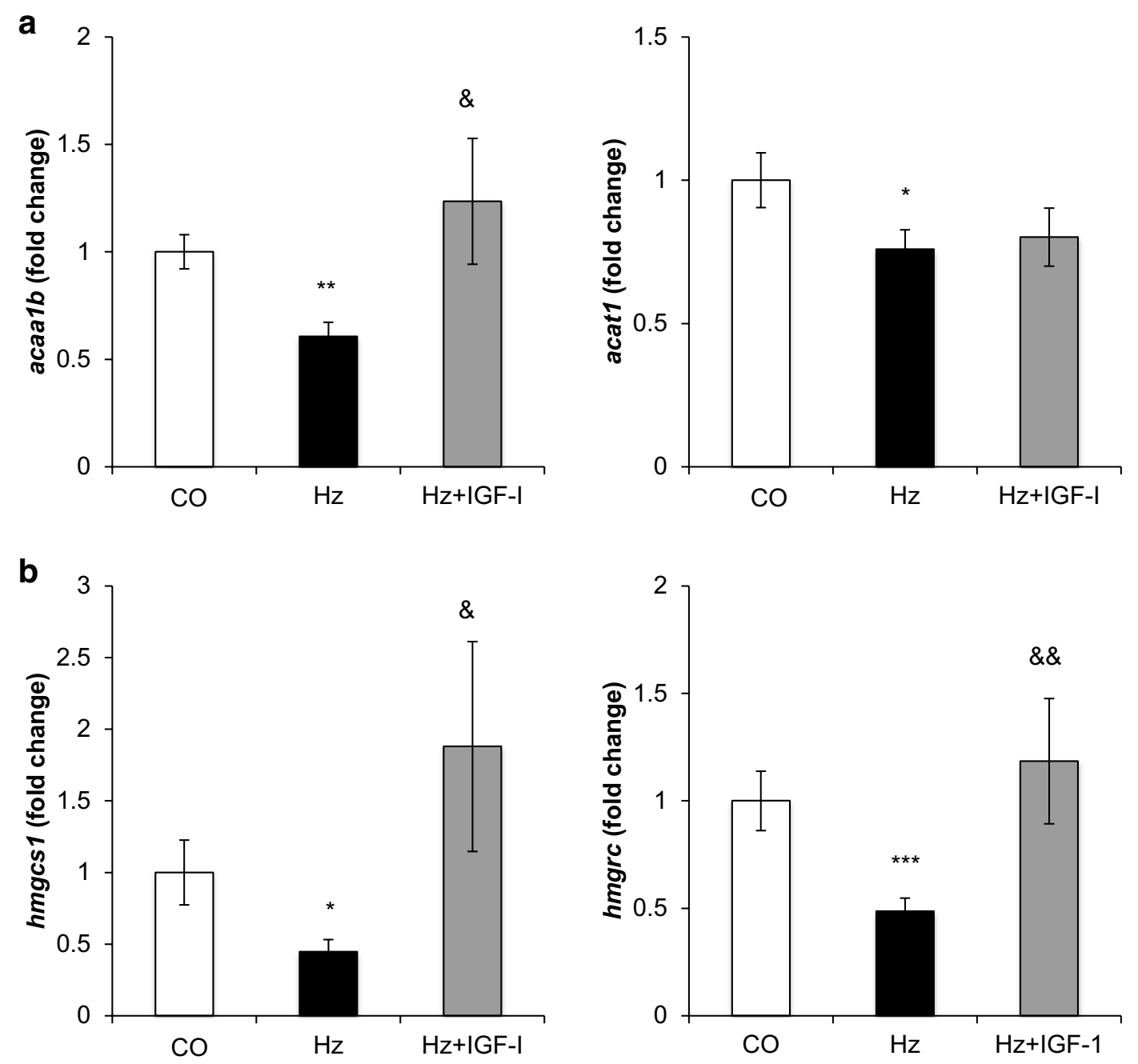

Fig. 3 Liver expression of genes implicated in lipid metabolism. a Gene expression of acaa 16 (Acetyl-CoA acyltransferase 1B) and acat1 (AcetylCoA acetyltransferase 1), implicated in lipid catabolism; $\mathbf{b}$ liver expression of the genes related to lipid synthesis hmgcs 1 (3-Hidroxi-3-metilglutarilCoA -sinthetase 1) and hmgrc (3-hydroxy-3-methylglutaryl-CoA reductase). All determined by RT-qPCR and expressed as relative values compared to controls (fold change). ${ }^{* *} p<0.001,{ }^{* *} p<0.01,{ }^{*} p<0.05 \mathrm{vs}$. CO; ${ }^{*}{ }^{*} p<0.01,{ }^{\&} p<0.05 \mathrm{vs}$. Hz

As aforementioned, untreated $\mathrm{Hz}$ mice $28 \pm 6$ weeks old showed hyperglycemia as compared to controls and $\mathrm{Hz}+\mathrm{IGF}-1$. Interestingly a similar finding was reported in aging rats, which showed low circulating levels of IGF-1 [7]. Unfortunately, in the present work insulin measurements and HOMA assessments are absent due to the little volume of blood that can be extracted from mice.

Results in this paper are in accordance with observations from other authors. It has been recently reported that a postprandial hyperglycemia in patients with Laron Syndrome was due to chronic IGF-1 deficiency and was reversed by IGF-1 replacement therapy [40].
Laron and Weinberger reported in 2004 two cases of untreated patients with congenital IGF-1 deficiency (Laron Syndrome), who developed T2D when they reached 39 and 41 years of age [42]. In our experience (data not published yet), this clinical development in never-treated patients with Laron Syndrome is quite frequent when other factors (especially diet) converge. Another recent study found that sensitivity to T2D is gender dependent in mice with impaired IGF-1 actions, showing that without high fat diet feeding males tend to develop glucose intolerance with age along with insulin resistance, which occurred in both males and females [43]. 

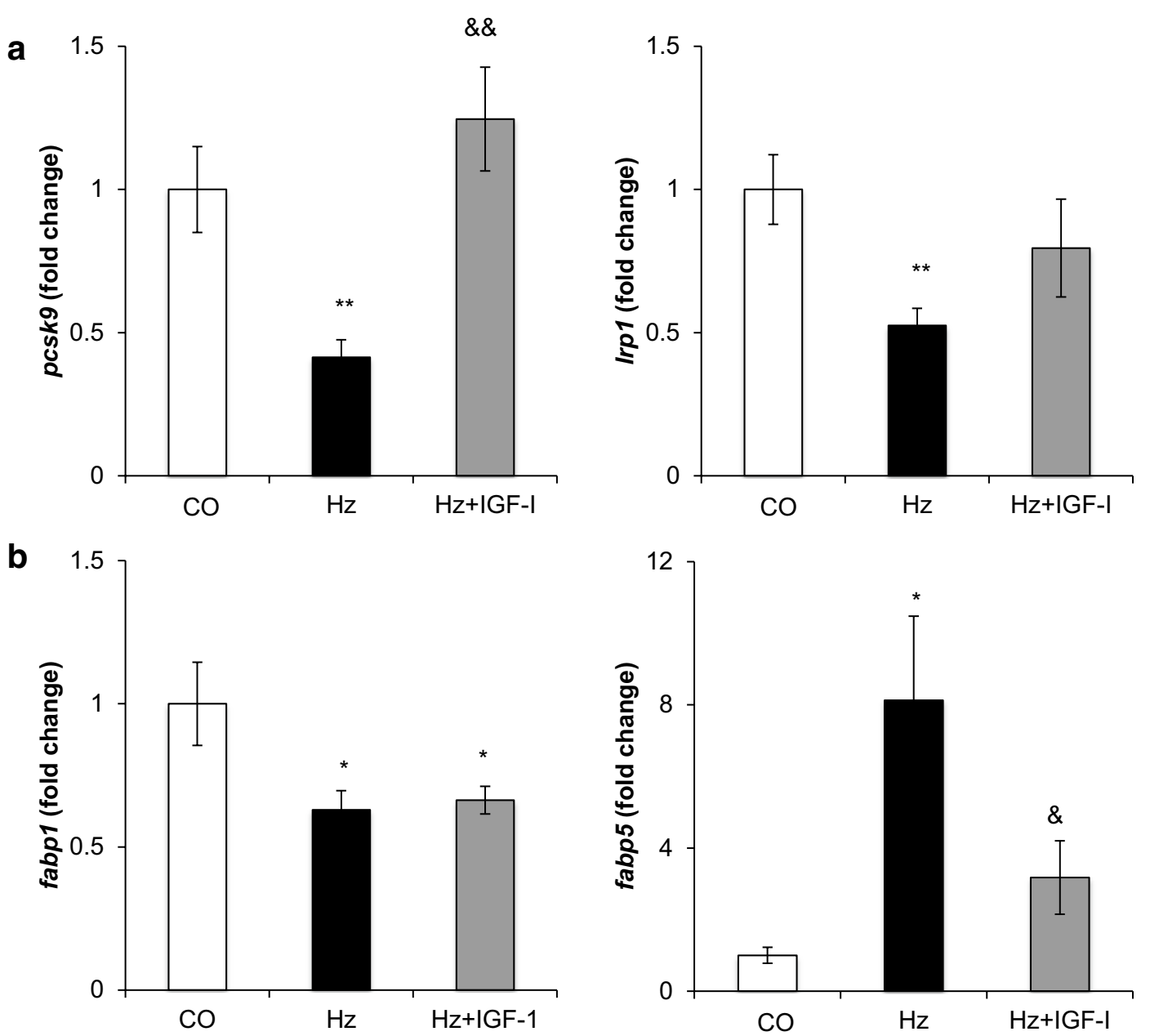

c

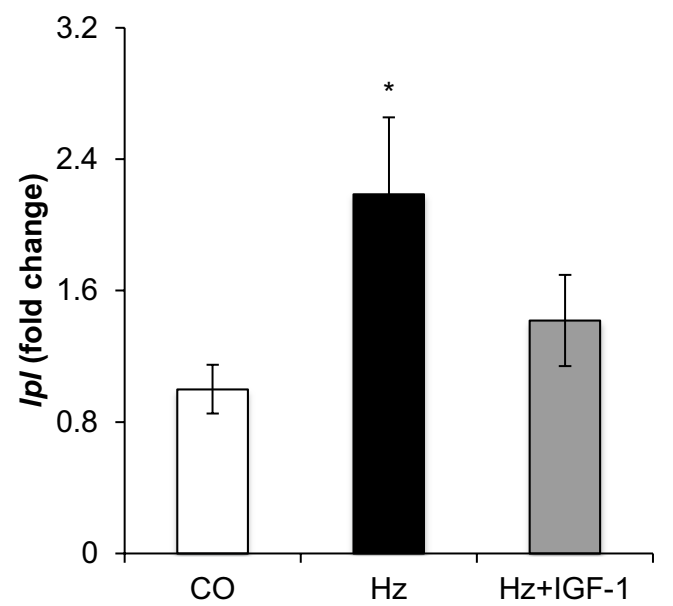

Fig. 4 Liver genes implicated in lipid transport. a Genes related to low density lipoprotein receptor-related protein synthesis: pcsk9 (Proprotein convertase subtilisin/kexin type 9) and Irp1 (Low density lipoprotein receptor-related protein 1); b expression of the genes related to fatty acid transport fabp 1 (Fatty acid binding protein 1) and fabp5 (Fatty acid binding protein 5); and $\mathbf{c}$ the gene related to triacylglycerol catabolism /p/ (Lipoprotein lipase). All determined by RT-qPCR and expressed as relative values compared to controls (fold change). ${ }^{* *} p<0.01,{ }^{*} p<0.05 \mathrm{vs}$. CO; ${ }^{\& \&} p<0.01$, $\&_{p}<0.05 \mathrm{vs} . \mathrm{Hz}$ 
Table 4 Liver expression of genes related to lipid metabolism

\begin{tabular}{|c|c|c|c|c|c|}
\hline Protein & Gene & $\begin{array}{l}\text { Hz vs. WT } \\
\text { (fold change) }\end{array}$ & $p$ value & $\begin{array}{l}\mathrm{Hz}+\text { IGF vs. Hz } \\
\text { (fold change) }\end{array}$ & p value \\
\hline Acetyl-Coenzyme A acyltransferase 1B & (Acaalb) & -4.04 & 0.002 & $\underline{2.28}$ & 0.00012 \\
\hline Acetyl-Coenzyme A acetyltransferase 1 & (Acat1) & -1.62 & 0.00006 & 1.21 & 0.017 \\
\hline Acetyl-Coenzyme A acetyltransferase 2 & (Acat2) & -1.50 & 0.04 & 1.34 & 0.02 \\
\hline Acyl-Coenzyme A oxidase 1, palmitoyl & $(A \cos 1)$ & $=1.70$ & 0.004 & 1.14 & 0.13 \\
\hline Acyl-CoA synthetase long-chain family member 1 & $($ Acs/1) & -2.20 & 0.0001 & $\underline{1.85}$ & 0.011 \\
\hline Acyl-CoA synthetase long-chain family member 3 & $(A c s / 3)$ & -1.96 & 0.018 & -1.06 & 0.19 \\
\hline Acyl-CoA synthetase medium-chain family $\mathrm{m} 2$ & (Acsm2) & -1.09 & 0.57 & 1.50 & 0.002 \\
\hline Acyl-CoA thioesterase 9 & $(A \cot 9)$ & 1.77 & 0.008 & -1.70 & 0.006 \\
\hline Cytochrome b5 reductase 3 & (Cyb5r3) & -1.52 & 0.04 & 1.46 & 0.03 \\
\hline $\begin{array}{l}\text { Phenylalkylamine Ca2+ antagonist (emopamil) binding } \\
\text { protein }\end{array}$ & (Ebp) & 1.49 & 0.13 & -1.16 & 0.21 \\
\hline 3-hydroxy-3-methylglutaryl-Coenzyme A reductase & (Hmgcr) & -2.77 & 0.0018 & 1.37 & 0.003 \\
\hline 3-hydroxy-3-methylglutaryl-Coenzyme A synthase1 & (Hmgcs1) & -1.49 & 0.019 & 1.45 & 0.04 \\
\hline Isopentenyl-diphosphate delta isomerase & (Idi1) & -1.49 & 0.013 & 1.38 & 0.02 \\
\hline Mevalonate (diphospho) decarboxylase & $(M v d)$ & -2.13 & 0.002 & $\underline{1.69}$ & 0.01 \\
\hline ATP-binding cassette, sub-family G (WHITE), member 1 & $(A b c g 1)$ & $\underline{1.83}$ & 0.004 & -1.66 & 0.05 \\
\hline Aldo-keto reductase family 1 , member D1 & (Akrld1) & -2.36 & 0.0002 & 1.21 & 0.018 \\
\hline Cytochrome P450, family 46, subfamily a, polypeptide 1 & (Сур46a1) & -1.77 & 0.004 & 1.01 & 0.17 \\
\hline Cytochrome P450, family 7, subfamily a, polypeptide 1 & (Сур7a1) & -2.76 & 0.0002 & 1.54 & 0.0013 \\
\hline Very low density lipoprotein receptor & $(V / d l r)$ & -3.12 & 0.0002 & 1.20 & 0.02 \\
\hline Low density lipoprotein receptor-related protein 1 & (Lrp1) & -1.49 & 0.0004 & 1.13 & 0.58 \\
\hline Proprotein convertase subtilisin/kexin type 9 & (Pcsk9) & -1.59 & 0.03 & 1.45 & 0.03 \\
\hline Fatty acid binding protein 1 , liver & (Fabp1) & -1.53 & 0.03 & 1.50 & 0.007 \\
\hline Fatty acid binding protein 5 , epidermal & (Fabp5) & $\underline{5.06}$ & 0.0002 & -2.27 & 0.006 \\
\hline Lipoprotein lipase & $(L p l)$ & 2.02 & 0.0012 & -2.50 & 0.002 \\
\hline
\end{tabular}

Control group, WT mice; Hz group including untreated mice with partial IGF-1 deficiency; Hz + IGF-1 group: Hz mice treated with low doses of IGF-1 during 10 days. Underlined values correspond to those with a fold-change $>1.5$, considered as a significant variation in the gene expression

In addition, untreated $\mathrm{Hz}$ mice exhibit a significant reduction in the hepatic expression of $a c l y$, which was normalized by IGF-1 replacement therapy. Acly encodes ATP-citrate lyase, one of the two cytosolic enzymes that synthesize acetyl-CoA. Because acetyl-CoA is an essential building block for cholesterol and triglycerides, acly has been considered a therapeutic target for hyperlipidemias and obesity [44]. In the present work untreated $\mathrm{Hz}$ mice with a tightly controlled diet and $28 \pm 6$ weeks old, showed increased circulating levels both triglycerides and cholesterol (Table 1), which the IGF-1 replacement therapy improved.

Accordingly, results in this paper describe a decreased expression of genes encoding several enzymes involved in lipid metabolism: acaa $1 b$ (acetyl-CoA acyltransferase 1B), acat 1 (acetyl-CoA acetyltransferase 1) (Fig. 3a). Acaa $1 b$ encodes an enzyme operative in the beta-oxidation system of the peroxisomes. Acetyl-CoA acyltransferase 1 is involved in the regulation of genes encoding cholesterol biosynthesis enzymes in the liver, suggesting that the peroxisome could be a promising candidate for the correction of cholesterol imbalance in dyslipidemia [45].

These data suggest a relevant function for IGF-1 in $\beta$-oxidation and cholesterol synthesis. On the other hand, two key enzymes for cholesterol biosynthesis were found reduced in the untreated $\mathrm{Hz}$ group and reverted by IGF-1 therapy: hmgcr (3-hydroxy-3-methylglutarylCo-A reductase-HMG-CoA reductase), and hmgcs1 (3-hydroxy-3-methylglutaryl-CoA synthase 1-HMGCoA synthase 1) (Fig. 3b).

The reaction catalyzed by HMG-CoA reductase is ratelimiting for cholesterol synthesis. This enzyme is highly regulated and is a target for pharmaceutical intervention to control hypercholesterolemia [46]. HMG-CoA reductase catalyzes the production of mevalonate from HMG-CoA. The carboxyl group of hydroxymethylglutarate linked by an ester bond to the thiol of Co-A is first reduced to an aldehyde and then to an alcohol. NADPH serves as a reductant in the 2-step reaction [47]. Mevaldehyde is thought to be an active site intermediate, following the first reduction and the release of CoA [47-49]. 
The enzyme HMG-CoA synthase catalyzes the condensation of an acetoacetyl-CoA and an acetyl-CoA to form HMG-CoA plus free CoA. HMG-CoA synthase activity is found both in the cytosol and in the mitochondria. The HMG-CoA produced by the cytosolic HMG-CoA synthase is converted to mevalonate by the action of HMG-CoA reductase. This reaction starts the isoprenoid pathway, whose main end-product is cholesterol [50].

Although results in this study show a diminished capability for IGF-1 deficient mice in cholesterol synthesis, as hmgcr, hmgcs1 and acly (enzymes involved in cholesterol synthesis) are downregulated, augmented serum cholesterol levels were found. This fact could be explained by the downregulation of lrp1 (LDL-receptor related protein 1) and pcsk9 (proprotein convertase subtilisin/Kesin type 9) both LDL-receptor related proteins, which could be impairing reverse cholesterol transport from the diet.

Moreover, results regarding lipid metabolism are in accordance with previous studies from this group undertaken in murine aging model, which sustain that IGF-1 and cholesterol have an inverse correlation [7] and are also associated with a mitochondrial dysfunction [51], reversible with IGF-1 treatment. Contrarily, studies undertaken in adult humans [52] disagree with such finding, suggesting that IGF-1 does not have an important role in cholesterol metabolism, but, however, agreed when they found that IGF-1 levels and triglycerides were inversely correlated [52].

On the other hand, a study undertaken in adult individuals showed that IGF-1 levels were positively related with HDL concentrations [52]. Also, in animal models it has been observed that IGF-1 gene expression is higher in adipose tissue compared to other organs [53]. This is in accordance with the fact that IGF-1 could have a lipolytic paracrine effect on adipocytes [54].

IGF-1 circulating levels decline with age. Previously it has been reported that aging rats showed low IGF-1 circulating levels associated to hyperlipidemia (cholesterol and triglycerides), hyperglycemia with insulin resistance [7], as well as an increase of peroxidative liver damage and mitochondrial dysfunction [51]. The exogenous administration of IGF-1, at low doses (similar to those used in the present work), restored IGF-1 serum levels reducing dyslipidemia and insulin resistance, oxidative liver damage and mitochondrial dysfunction [7, 51].

Likewise results in this paper show an increase in MDA homogenate levels, indicative of oxidative damage in the liver of untreated mice with partial IGF-1 deficiency as compared to controls. In addition, IGF-1 therapy induced a reduction of MDA levels even under control values, suggesting an antioxidant activity of IGF-1 according to previously reported results [8].
One recent large-scale community based Framingham Heart Study suggested that lower IGF-1 levels are associated with insulin resistance and MetS [55]. All of these data are in accordance with the observations of reduced IGF-1 levels in individuals with MetS and its various components [14].

The primary condition of IGF-1 deficiency in humans is Laron Syndrome, characterized by low body weight and stature, similar to the one found in mice. However, more recently, IGF-1 deficiency has been associated with an increased prevalence of obesity. A general finding is that obese patients that fulfill the criteria for MetS presenting low IGF-1 plasma levels, tend to develop a worse cardiovascular disease outcome than those with mid-normal to high-normal IGF-1 level [32]. Findings in this work support this idea as metabolic deregulation has been suggested. Although mice with partial IGF-1 deficiency exhibit retarded body weight gain, they have not been exposed to a high fat diet or any other external insult, as they were kept within strictly controlled conditions, thus being IGF-1 deficiency the only feasible component causing metabolic imbalance. Such deregulation found could render these animals to the deleterious effects of obesity if fed with a high fat diet, presumably leading to metabolic syndrome.

In fact, circulating IGF-1 levels are reported to be inversely correlated with the risk of cardiovascular diseases [14]. For example, elderly patients with low circulating IGF-1 levels are at a much higher risk of ischemic stroke and congestive heart failure [56].

Visceral adipose tissue is inversely correlated with circulating IGF-1 levels [33]. In this sense, it was also reported that obesity (always visceral obesity) found in patients with Laron Syndrome is not due to either excessive nutritional intake nor hypometabolism [57].

\section{Conclusions}

In conclusion, our present data, supported by literature evidence, indicates that IGF-1 deficiency is deeply involved in the establishment of MetS while not a definitive factor in its development. Findings in this paper offer a plausible explanation for some of the mechanisms linking IGF-1 deficiency to the establishment of MetS and suggest this condition to be a novel candidate for IGF-1 replacement therapy.

\section{Abbreviations}

CoA: coenzyme A; ADP: adenosine diphosphate; Akt (PKB): protein kinase B; CO: control; DM: diabetes mellitus; FFA: free fatty acids; G6Pase: glucose6-phosphatase; G6PD: glucose 6 phosphate dehydrogenase; HDL: high density lipoprotein; Hz: heterozygotes; IGF-1: insulin-like growth factor-1; IGF1R: IGF-1 receptor; IGFBP: insulin-like growth factor binding protein; LDL: low density lipoprotein; MDA: malondialdehyde; MetS: metabolic syndrome; T2D: type 2 diabetes; PCR: polymerase chain reaction; PKC: protein kinase C; 
PI3K: phosphoinositide 3-kinase; IR: insulin receptor; VLDL: very low density lipoprotein; WT: wild type.

\section{Authors' contributions}

RDIJ selected the genes of clinical interest, results interpretation and manuscript writing; C-Cl conceived and designed the study and experimental model, selected the genes of clinical importance, data analysis, discussion, conclusions and manuscript writing; OS-RM determinations in sera and in vivo treatment; AGA prepared the samples, contributed in microarray and RT-PCR analysis, contributed to manuscript writing; S-YC genotype characterization and in vivo work; G-ML in vivo work and preparation of the samples; $\mathrm{M}-\mathrm{EI}$ in vivo protocol procedure; G-MM preparation of the samples and the end of the treatment, contribution in microarray and RT-PCR analysis; L-DVJ discussion of results and references; PJE coordination of the in vivo experiments; M-MU coordination of molecular biology analysis, functional gene cluster and statistical study. All authors read and approved the final manuscript.

\section{Author details}

${ }^{1}$ Escuela de Medicina, Tecnologico de Monterrey, Avenida Morones Prieto No. 3000 Pte. Col. Los Doctores, 64710 Monterrey, Nuevo León, México. ${ }^{2}$ Fundación de Investigación HM Hospitales, Plaza. del Conde del Valle de Súchil 16, 28015 Madrid, Spain. ${ }^{3}$ Department of Medical Physiology, Institute of Applied Molecular Medicine (IMMA), School of Medicine, University CEU San Pablo, Calle Boadilla del Monte s/n, km 5,3, 28668 Madrid, Spain.

\section{Acknowledgements}

The authors would like to express their gratitude to Prof. A. Efstratiadis (Columbia University, College of Physicians and Surgeons, New York, USA) for kindly providing the transgenic IGF-1 mice and to Chiron Company (Emeryville, CA) for granting the recombinant human IGF-I used in this study. A very special thank to Ms. Susana Arahuetes and Ms. Paloma Fernandez for their expert technical assistance. We are also very grateful to Karl Steinmetz for the English revision of the manuscript and Jesús Ortiz for his efficient contribution with figures. This work was supported by grants from "Fundación de Investigación HM Hospitales" and "Tecnológico de Monterrey".

\section{Competing interests}

The authors declare that they have no competing interests.

Received: 10 June 2015 Accepted: 1 October 2015

Published online: 14 October 2015

\section{References}

1. Le Roith D. Seminars in medicine of the Beth Israel Deaconess Medical Center. Insulin-like growth factors. N Engl J Med. 1997;336(9):633-40.

2. Clemmons DR. Metabolic actions of insulin-like growth factor-l in normal physiology and diabetes. Endocrinol Metab Clin North Am. 2012;41:42543 (vii-viii).

3. Clemmons DR. The relative roles of growth hormone and IGF-1 in controlling insulin sensitivity. J Clin Invest. 2004;113:25-7.

4. Yakar S, Setser J, Zhao H, Stannard B, Haluzik M, Glatt V, Bouxsein ML, Kopchick JJ, LeRoith D. Inhibition of growth hormone action improves insulin sensitivity in liver IGF-1-deficient mice. J Clin Invest. 2004;113:96-105.

5. Holt Rl, Simpson HL, Sonksen PH. The role of the growth hormoneinsulin-like growth factor axis in glucose homeostasis. Diabet Med. 2003;20:3-15

6. Saukkonen T, Shojaee-Moradie F, Williams RM, Amin R, Yuen KC, Watts A, Acerini CL, Umpleby AM, Dunger DB. Effects of recombinant human IGF-I/IGF-binding protein-3 complex on glucose and glycerol metabolism in type 1 diabetes. Diabetes. 2006;55:2365-70.

7. Garcia-Fernandez M, Delgado G, Puche JE, Gonzalez-Baron S, Castilla Cortazar I. Low doses of insulin-like growth factor I improve insulin resistance, lipid metabolism, and oxidative damage in aging rats. Endocrinology. 2008;149:2433-42.

8. Castilla-Cortazar I, Garcia M, Muguerza B, Quiroga J, Perez R, Santidrian $S$, Prieto J. Hepatoprotective effects of insulin-like growth factor I in rats with carbon tetrachloride-induced cirrhosis. Gastroenterology. 1997;113:1682-91.
9. Liu W, Li WB, Chen ZJ, Rong ZH, Chang LW. Protective effects of IGF-1 on cortical nerve cells of neonatal rats under oxidative stress. Zhongguo Dang Dai Er Ke Za Zhi. 2014;16:203-7.

10. Mallea-Gil MS, Ballarino MC, Spiraquis A, Iriarte M, Kura M, Gimenez S, Oneto A, Guitelman M, Machado R, Miguel CM. IGF-1 levels in different stages of liver steatosis and its association with metabolic syndrome. Acta Gastroenterol Latinoam. 2012;42:20-6.

11. Moses AC. Insulin resistance and type 2 diabetes mellitus: is there a therapeutic role for IGF-1? Endocr Dev. 2005;9:121-34.

12. Malik J, Stulc T, Wichterle D, Melenovsky V, Chytilova E, Lacinova Z, Marek J, Ceska R. Hyperlipidemia is associated with altered levels of insulin-like growth factor-I. Physiol Res. 2008;57:919-25.

13. Franco C, Bengtsson BA, Johannsson G. The GH/IGF-1 axis in obesity: physiological and pathological aspects. Metab Syndr Relat Disord. 2006:4:51-6.

14. Ren J, Anversa P. The insulin-like growth factor I system: physiological and pathophysiological implication in cardiovascular diseases associated with metabolic syndrome. Biochem Pharmacol. 2015;93:409-17.

15. Cameron AJ, Shaw JE, Zimmet PZ. The metabolic syndrome: prevalence in worldwide populations. Endocrinol Metab Clin North Am. 2004;33:351-75 (table of contents).

16. Grundy SM. Metabolic syndrome pandemic. Arterioscler Thromb Vasc Biol. 2008;28:629-36.

17. Jeppesen J, Hansen TW, Rasmussen S, Ibsen H, Torp-Pedersen C, Madsbad S. Insulin resistance, the metabolic syndrome, and risk of incident cardiovascular disease: a population-based study. J Am Coll Cardiol. 2007;49:2112-9.

18. Hu G, Qiao Q, Tuomilehto J, Balkau B, Borch-Johnsen K, Pyorala K, Group DS. Prevalence of the metabolic syndrome and its relation to all-cause and cardiovascular mortality in nondiabetic European men and women. Arch Intern Med. 2004;164:1066-76.

19. Sattar N, McConnachie A, Shaper AG, Blauw GJ, Buckley BM, de Craen AJ, Ford I, Forouhi NG, Freeman DJ, Jukema JW, et al. Can metabolic syndrome usefully predict cardiovascular disease and diabetes? Outcome data from two prospective studies. Lancet. 2008;371:1927-35.

20. Hanson RL, Imperatore G, Bennett PH, Knowler WC. Components of the "metabolic syndrome" and incidence of type 2 diabetes. Diabetes. 2002;51:3120-7.

21. Grundy SM. Metabolic syndrome: connecting and reconciling cardiovascular and diabetes worlds. J Am Coll Cardiol. 2006;47:1093-100.

22. Lebovitz HE. Type 2 diabetes: an overview. Clin Chem. 1999;45:1339-45.

23. Meigs JB, Rutter MK, Sullivan LM, Fox CS, D'Agostino RB Sr, Wilson PW. Impact of insulin resistance on risk of type 2 diabetes and cardiovascular disease in people with metabolic syndrome. Diabetes Care. 2007;30:1219-25.

24. Kim HJ, Kim HJ, Lee KE, Kim DJ, Kim SK, Ahn CW, Lim SK, Kim KR, Lee HC, Huh KB, Cha BS. Metabolic significance of nonalcoholic fatty liver disease in nonobese, nondiabetic adults. Arch Intern Med. 2004;164:2169-75.

25. Kotronen A, Westerbacka J, Bergholm R, Pietilainen KH, Yki-Jarvinen $\mathrm{H}$. Liver fat in the metabolic syndrome. J Clin Endocrinol Metab. 2007;92:3490-7.

26. Castilla-Cortazar I, Guerra L, Puche JE, Munoz U, Barhoum R, Escudero E, Lavandera JL. An experimental model of partial insulin-like growth factor-1 deficiency in mice. J Physiol Biochem. 2014;70:129-39.

27. Liu JP, Baker J, Perkins AS, Robertson EJ, Efstratiadis A. Mice carrying null mutations of the genes encoding insulin-like growth factor I (lgf-1) and type 1 IGF receptor (Igf1r). Cell. 1993;75:59-72.

28. Irizarry RA, Bolstad BM, Collin F, Cope LM, Hobbs B, Speed TP. Summaries of affymetrix GeneChip probe level data. Nucleic Acids Res. 2003;31:e15.

29. Johnson WE, Li C, Rabinovic A. Adjusting batch effects in microarray expression data using empirical Bayes methods. Biostatistics. 2007:8:118-27.

30. Livak KJ, Schmittgen TD. Analysis of relative gene expression data using real-time quantitative PCR and the 2(-Delta Delta $C(T)$ ) Method. Methods. 2001;25:402-8.

31. Guerra-Menendez L, Sadaba MC, Puche JE, Lavandera JL, de Castro LF, de Gortazar AR, Castilla-Cortazar I. IGF-I increases markers of osteoblastic activity and reduces bone resorption via osteoprotegerin and RANKligand. J Transl Med. 2013;11:271. 
32. Saydah S, Ballard-Barbash R, Potischman N. Association of metabolic syndrome with insulin-like growth factors among adults in the US. Cancer Causes Control. 2009;20:1309-16.

33. Savastano S, Di Somma C, Barrea L, Colao A. The complex relationship between obesity and the somatropic axis: the long and winding road. Growth Horm IGF Res. 2014;24:221-6.

34. Akanji AO, Smith RJ. The insulin-like growth factor system, metabolic syndrome, and cardiovascular disease risk. Metab Syndr Relat Disord. 2012;10:3-13.

35. Postic C, Dentin R, Girard J. Role of the liver in the control of carbohydrate and lipid homeostasis. Diabetes Metab. 2004;30:398-408.

36. O'Brien RM, Granner DK. Regulation of gene expression by insulin. Physiol Rev. 1996;76:1109-61.

37. Frystyk J. Free insulin-like growth factors - measurements and relationships to growth hormone secretion and glucose homeostasis. Growth Horm IGF Res. 2004;14:337-75.

38. Hanaire-Broutin H, Sallerin-Caute B, Poncet MF, Tauber M, Bastide R, Rosenfeld R, Tauber JP. Insulin therapy and GH-IGF-I axis disorders in diabetes: impact of glycaemic control and hepatic insulinization. Diabetes Metab. 1996;22:245-50.

39. Bereket A, Lang CH, Wilson TA. Alterations in the growth hormone-insulin-like growth factor axis in insulin dependent diabetes mellitus. Horm Metab Res. 1999;31:172-81.

40. Latrech H, Simon A, Beltrand J, Souberbielle JC, Belmejdoub G, Polak M. Postprandial hyperglycemia corrected by IGF-I (Increlex(R)) in Laron syndrome. Horm Res Paediatr. 2012;78:193-200.

41. Lee IK. The role of pyruvate dehydrogenase kinase in diabetes and obesity. Diabetes Metab J. 2014;38:181-6.

42. Laron Z, Weinberger D. Diabetic retinopathy in two patients with congenital IGF-I deficiency (Laron syndrome). Eur J Endocrinol. 2004;151:103-6.

43. Garg N, Thakur S, McMahan CA, Adamo ML. High fat diet induced insulin resistance and glucose intolerance are gender-specific in IGF-1R heterozygous mice. Biochem Biophys Res Commun. 2011:413:476-80.

44. Beigneux AP, Kosinski C, Gavino B, Horton JD, Skarnes WC, Young SG. ATPcitrate lyase deficiency in the mouse. J Biol Chem. 2004;279:9557-64.

45. Fidaleo M, Arnauld S, Clemencet MC, Chevillard G, Royer MC, De Bruycker M, Wanders RJ, Athias A, Gresti J, Clouet P, et al. A role for the peroxisomal 3-ketoacyl-CoA thiolase B enzyme in the control of PPARalphamediated upregulation of SREBP-2 target genes in the liver. Biochimie. 2011;93:876-91.

46. Chen Y, Ku H, Zhao L, Wheeler DC, Li LC, Li Q, Varghese Z, Moorhead JF, Powis $\mathrm{SH}$, Huang A, Ruan XZ. Inflammatory stress induces statin resistance by disrupting 3-hydroxy-3-methylglutaryl-CoA reductase feedback regulation. Arterioscler Thromb Vasc Biol. 2014;34:365-76.
47. Wang W, Tong TJ. The key enzyme of cholesterol synthesis pathway: HMG-CoA reductase and disease. Sheng Li Ke Xue Jin Zhan. 1999;30:5-9.

48. Steussy CN, Critchelow CJ, Schmidt T, Min JK, Wrensford LV, Burgner JW 2nd, Rodwell VW, Stauffacher CV. A novel role for coenzyme A during hydride transfer in 3-hydroxy-3-methylglutaryl-coenzyme A reductase. Biochemistry. 2013;52:5195-205.

49. Ness GC, Chambers CM. Feedback and hormonal regulation of hepatic 3-hydroxy-3-methylglutaryl coenzyme A reductase: the concept of cholesterol buffering capacity. Proc Soc Exp Biol Med. 2000;224:8-19.

50. Rokosz LL, Boulton DA, Butkiewicz EA, Sanyal G, Cueto MA, Lachance PA, Hermes JD. Human cytoplasmic 3-hydroxy-3-methylglutaryl coenzyme A synthase: expression, purification, and characterization of recombinant wild-type and Cys129 mutant enzymes. Arch Biochem Biophys. 1994;312:1-13.

51. Puche JE, Garcia-Fernandez M, Muntane J, Rioja J, Gonzalez-Baron S, Castilla Cortazar I. Low doses of insulin-like growth factor-I induce mitochondrial protection in aging rats. Endocrinology. 2008;149:2620-7.

52. Succurro E, Arturi F, Grembiale A, lorio F, Laino I, Andreozzi F, Sciacqua A, Hribal ML, Perticone F, Sesti G. Positive association between plasma IGF1 and high-density lipoprotein cholesterol levels in adult nondiabetic subjects. Eur J Endocrinol. 2010;163:75-80.

53. Yakar S, Liu JL, Stannard B, Butler A, Accili D, Sauer B, LeRoith D. Normal growth and development in the absence of hepatic insulin-like growth factor I. Proc Natl Acad Sci USA. 1999;96:7324-9.

54. Boucher J, Mori MA, Lee KY, Smyth G, Liew CW, Macotela Y, Rourk M, Bluher M, Russell SJ, Kahn CR. Impaired thermogenesis and adipose tissue development in mice with fat-specific disruption of insulin and IGF-1 signalling. Nat Commun. 2012;3:902.

55. Lam CS, Chen MH, Lacey SM, Yang Q, Sullivan LM, Xanthakis V, Safa R, Smith HM, Peng X, Sawyer DB, Vasan RS. Circulating insulin-like growth factor-1 and its binding protein-3: metabolic and genetic correlates in the community. Arterioscler Thromb Vasc Biol. 2010;30:1479-84.

56. Troncoso R, Ibarra C, Vicencio JM, Jaimovich E, Lavandero S. New insights into IGF-1 signaling in the heart. Trends Endocrinol Metab. 2014;25:128-37.

57. Ginsberg S, Laron Z, Bed MA, Vaisman N. The obesity of patients with laron syndrome is not associated with excessive nutritional intake. Obes Res Clin Pract. 2009;3:1-52.

\section{Submit your next manuscript to BioMed Central and take full advantage of:}

- Convenient online submission

- Thorough peer review

- No space constraints or color figure charges

- Immediate publication on acceptance

- Inclusion in PubMed, CAS, Scopus and Google Scholar

- Research which is freely available for redistribution

Submit your manuscript at 